\title{
Geoinformational prognostic model of mudflows hazard and mudflows risk for the territory of Ukrainian Carpathians
}

\author{
Tetiana B. Chepurna*, Eduard D. Kuzmenko, Igor V. Chepurnyj \\ Department of Geotehnohenic safety and Geoinformatics, Institute of Geology and Geophisics, National \\ Technical University of Oil and Gas, 15 Karpatska street, Ivano-Frankivsk, Ukraine \\ *corresponding author: t.misak@yandex.ua
}

Received: $1^{\text {st }}$ August, 2016

Accepted: $25^{\text {th }}$ May, 2017

\begin{abstract}
The article is devoted to the geological issue of the space-time regional prognostication of mudflow hazard. The methodology of space-time prediction of mudflows hazard by creating GIS predictive model has been developed. Using GIS technologies the relevant and representative complex of significant influence of spatial and temporal factors, adjusted to use in the regional prediction of mudflows hazard, were selected. Geological, geomorphological, technological, climatic, and landscape factors have been selected as spatial mudflow factors. Spatial analysis is based on detection of a regular connection of spatial factor characteristics with spatial distribution of the mudflow sites. The function of a standard complex spatial index (SCSI) of the probability of the mudflow sites distribution has been calculated. The temporal, long-term prediction of the mudflows activity was based on the hypothesis of the regular reiteration of natural processes. Heliophysical, seismic, meteorological, and hydrogeological factors have been selected as time mudflow factors. The function of a complex index of long standing mudflow activity (CIMA) has been calculated. The prognostic geoinformational model of mudflow hazard up to 2020 year, a year of the next peak of the mudflows activity, has been created. Mudflow risks have been counted and carogram of mudflow risk assessment within the limits of administrativeterritorial units has been built for 2020 year.
\end{abstract}

Key words: mudflows, mudflows hazard, temporal factors, spatial factors, geoinformational model

\section{Introduction}

In the Carpathian region, there are three basins with mudflow activity. Within these basins, 390 mudflow streams were marked, which cover an area of $3917.4 \mathrm{~km}^{2}$. In Transcarpathia almost $40 \%$ of river basins are characterized by the development of the mudflow processes, more than 270 streams were fixed with mudflows (total area nearly $1083 \mathrm{~km}^{2}$ ) (Krasnook 2016).

Fundamental researches in the study of mudflows are depicted in the works of Shekou, Conssot, De Wrachien, Gabet, Iverson, Cora, Matthias, Takahashi, and Zic. Important contributions have been made by renewed Ukrainian scientists such as Adamenko,
Kuzmenko, Oliferov and Rud'ko. Further development of this research theme has works connected with using of modern GIS technologies developed by Ivanik, Lukyanets, Kasiyanchuk, Kovalchuk, Susidko, Chepurna, Shevchuk.

The relevance of this issue is indicated by annual reports of international conferences and symposiums, most recently in the "6th International Conference of debris flow hazards mitigation: mechanics, prediction and assessment", held in Tsukuba in Japan in 2015.

In investigations dedicated towards mudflow issues, respective authors refer to weather and climate as the main mechanisms for the realization of the mudflow process. There are many prognostic methods based on 
relationships among the mudflow development, the influence of climate parameters and landslide processes (Iverson et al. 1997, Jakob and Hungr 2005, Xu 2008, Zic E. et al. 2015). Some methods and ideas from these researches were developed in current investigation.

The authors of this article have published a series of works (Chepurna 2011; Kuzmenko and Chepurna 2014) about the prognosis of mudflow activity, which solve specific aspects of the problem. The main findings and essential aspects of these investigations will be shared through this article.

\section{Purpose}

The purpose of these studies was to establish patterns of mudflow processes, depending on the factors that contribute to them and to the regional space-time prognosis of mudflow hazard with usage of geoinformational technologies. This methodology based on methodology of forecasting of exogenous geological processes proposed in work by Kuzmenko E. (Kuzmenko 2011).

In order to achieve this goal the following tasks are set:

- improvement of the methodology of regional spatial and temporal prognosis of exogenous geological processes for prognosis of mudflow hazard;

- selection of a relevant and representative complex of factors that influence on the spatial and temporal development of mudflows and assess the impact of each factor;

- calculation of SCSI function of mudflows sites distribution probability;

- identification and justification of the complex of factor characteristics as a quantitative measure of assessing of each factor impact;

- calculation of CIMA function;

- creation of geoinformation predictive mudflow hazard models for the year of the next maximum mudflow activation. Testing was conducted for the territory of the eastern part of Transcarpathia.

\section{Method}

The proposed process of creating a long-term space-time prognosis of mudflow hazard involves three main phases:

I. Calculation of SCSI function of mudflows sites distribution probability.

II. Calculation of multi-function of mudflow activity.

III. Creating of geoinformation models of predicting mudflow hazard.

The mathematical apparatus and well-known formulas were taken from work by Zhukov (Zhukov 2008). Other formulas - from the methodology proposed by Kuzmenko (Kuzmenko 2011).

I. Calculation of SCSI function was done at the following stages:

1. Creation of geoinformation mapping package base, which contains all possible information about factors, which could have some influence on mudflow processes.

2. Implementation of spatial analysis.

Distances to points and linear objects, which represented the selected factors, were calculated with the help of the integrated GIS package modules by using overlay operations, with the aim of further searching of appropriate connection between mudflow processes and factors. The infestation of watercourses by mudflow processes was calculated (formula 1) for observing the intensity of mudflow processes in accordance to factors impact, which were reflected in mapping through some polygonal objects (zones).

$U=\frac{\sum_{i=1}^{k} l_{i}}{\sum_{j=1}^{n} L_{j}}$, 
where $U$-infestation of zone; $l_{i}-$ the length of mudflow streams; $k$ - number of mudflow streams within the zone; $L_{j}-$ the length of watercourse; $n$ - number of watercourses within a given zone. Quantitative values which were calculated further will be called "factor characteristics".

3. Empirical detection and confirmation of the existence of a legitimate connection between the spatial distribution of mudflows and each of the factors.

Detection of a legitimate connection between the spatial distribution of mudflow sites and factors was performed through conformity of factor characteristics distribution in accordance to normal distribution. The procedure of taking the logarithm was applied to the values of factor characteristics, which had lognormal distribution.

The obligatory condition for usage in prognostic model of a certain factor was unique, which should be achieved by excluding the overlapping factors from the analysis.

4. Calculation of factor characteristics informativeness.

Calculations were based on a cross-correlation analysis. At this stage, pair correlation were calculated between the arrays of values of factor characteristic.

The coefficients of informativeness were calculated (formula 2) with the aim of confirmation of the right choice of factors and determination of weighted influence of each of them on a mudflow process.

$V_{j}=\frac{\sum_{j=1}^{k}\left|r_{i j}\right|}{\sum_{i=1}^{n} \sum_{j=1}^{k}\left|r_{i j}\right|} \cdot 100 \%$ where: $r_{i j}$ - a value of coefficient of pair correlation between $i$ and $j$ variables in the table of matrix of correlation coefficients. Factor characteristics, which had a coefficient of informativeness nearly zero, were eliminated from consideration.

\section{Calculation of SCSI function.}

The arrays of factor characteristic values are rationed in accordance to mean and middle quadratic deviation, with the aim of transformation of the values, which were expressed in individuals quantities into dimensionless contrast ratio.

Calculation of SCSI for every $i$ - mudflow site were executed by the formula

$Q_{i}=\sum_{j=1}^{k} z_{i j} \cdot V_{j}$,

where: $z_{i j}$ - the rationed value $j$ factor characteristic for $i$ - mudflow; $k$ - a number of factor characteristic, $V_{j}-$ a value of the coefficient of informativeness.

In such case the function of distribution of SCSI describes the curve of normal distribution.

$f\left(Q_{i}\right)=\frac{1}{\sigma \sqrt{2 \pi}} e^{-\frac{\left(Q_{i}-\mu\right)^{2}}{2 \cdot \sigma^{2}}}$,

where: $\mu-$ a mathematical expectation, $\sigma-$ standard deviation of $Q_{i}$.

For the converting of all values of the function in a way that it maximum value was equal to one it was multiplied by $\max \left(f\left(Q_{i}\right)\right)^{-1}$.

\section{Calculation of CIMA function.}

Level of mudflows activity in a certain year is conditioned by influence of factors, which determine this process. The first step at the temporal long-term mudflow activity model 
construction was choosing relevant temporal factors, which promoted the long-term activation of mudflows within given this area. Factors such as: climatic, seismic, hydrogeological and heliophysical were taken into account.

The next in the sequence was the analysis of time series.

1. Searching of periodicity at time series of factors with usage of autocorrelation function

$R_{f}(\tau)=\int_{-\infty}^{\infty} f(t) f(t-\tau) d t$,

where: a function $f(t)$ (time series of factor characteristic or mudflows activity) which integrates into the multiplication with complexly conjugated and displaced on certain time $\tau$; the same function $f(t)$.

2. Analysis of periodograms which were built on results of Fourier' transform, with the aim of confirmation of detected and hidden periods. The trigonometric series of Fourier is a presentation of random function of $f$ with a period $\tau$, as a series

$$
f(x)=\frac{a_{0}}{2}+\sum_{n=1}^{\infty}\left(a_{n} \cos (n x)+b_{n} \sin (n x)\right),
$$

where $a_{0}, a_{n}$ and $b_{n}$ are coefficients of function $f$, calculated after well-known formulas.

3. Realization of pair cross correlation between the series of mudflow activity and factors with the aim of exposure of their existent displacements in time and bringing to maximal in phase.

The coefficient of correlation $r_{x y}(k)$ is a correlation between two series: by mudflow activity $x$ and each of factors $y$, where the series of $x$ is displaced on lag of $k$ order :

$$
r_{x y}(k)=\frac{c_{x y}(k)}{s_{x} s_{y}}, \text { for } \mathrm{k}=0, \pm 1, \pm 2
$$

where: $c_{x y}(k)$ is a coefficient of pair cross correlation on the lag $k ; s_{x}, s_{y}$ are standard deviations of series.

\section{Calculation of CIMA for a forecasted year.}

The arrays of values of factor characteristic were rationed by standard deviation with the aim of transformation of the values shown in individual sizes, in the dimensionless indexes of contrast.

The calculation of CIMA for the prognosis year of $t$ was executed by formula

$$
\Omega_{t}=\sum_{j=1}^{m} z_{t j},
$$

where: $z_{t j}$ - the rationed value of $j$ factor characteristic in $t$ year; $m$ - a number of temporal factor characteristic. Summation was conducted between the displaced time series. We provide the functions $f\left(\Omega_{\mathrm{t}}\right)$ in appearance where 0 - mudflow activity is absent, 1 maximal mudflow activity. By the function $f\left(\Omega_{\mathrm{t}}\right)$ were determined $P\left(\Omega_{\mathrm{t}}\right)$ - probability of mudflow activity in the $t$ year.

\section{Creation of prognostic geoinformational model of mudflow hazard (PGMMD)}

Extrapolation of time series was proposed to be made in three ways: by the summation of the basic accordions, which were received throughout Fourier analysis; by neural networks; and by averaging a time series of integral index, taking into account the main mudflow activation period.

Confidence interval calculated for testing the reliability of the forecast.

PGMMD of the investigated territory was created on the basis of the regular grid. With the application of overlay analysis, the values of factor characteristic are taken off in every 
point of grid. The further expected values were compared to standard, and probability (mudflow hazard) $P\left(Q_{i}\right)$ was determined in the $i$ point.

By the formula 9 the mudflow hazard was calculated using mudflow hazard of $P(i, t)$ in space ( $i$ point on the surface with coordinates $(\mathrm{x}, \mathrm{y})$ and in time (in $t$ year)) .

$$
P_{i, t}=P\left(Q_{i}\right) \cdot P\left(\Omega_{t}\right)
$$

where: $P(Q i)$ - a value of probability of mudflow hazard in $i$ point; $P\left(\Omega_{i}\right)$ - a value of probability of mudflow activation in $t$ time.

Retroprognosis map of the year of last mudflow activity was built with the aim to control of quality of PGMMD. The prognosis of mudflow hazard was compared with actual mudflows.

The mean value of mudflow hazard of $i$ area was expected as

$\bar{P}_{i, t}=\frac{\sum_{n=1}^{m} P_{j, t}}{m}$

where: $\sum_{n=1}^{m} P_{j, t}$ - total probability of mudflow development within an area; $m$ - the number of points of the grid for which was calculated the spatial probability of mudflow development in the time $t$ within the selected area.

Under the adjusted collective mudflow risk for an area (region), one should understand the risk from mudflows, which takes into account: the average of spatial-temporal probability of development of mudflows; the proportion of area of mudflow alluvial fans over the investigated period and total area (as an index of maximal spatial exposure); the density of the population; and availability of the protective systems within the territory.

The formula of the adjusted collective mudflow risk (persons per square $\mathrm{km}$ ) for $i$ area in $t$ time) is
$\operatorname{Rpr}_{i, t}=\bar{P}_{i, t} \cdot N_{i} \cdot \frac{\sum_{n=1}^{k} s_{i}}{S_{i}{ }^{2}} \cdot Z_{i}$

where: $\bar{P}_{i, t}$ - a mean value of mudflow hazard for the region $i$ in $t$ time; $\sum_{n=1}^{k} s-$ a total area of mudflow alluvial fans over investigated time, $\mathrm{km}^{2} ; S_{i}$ - an area of $i$ region, $\mathrm{km}^{2} ; N_{i}$ - an amount of population in $i$ region, persons; $Z_{i}$ a coefficient that takes into account the presence of mudflow protective constructions.

\section{Testing of the proposed methodology of spatial prognosis}

An area of $4179 \mathrm{~km}^{2}$ within the territory of Ukrainian Carpathians, characterized by mudflow process development (Fig.1), was selected for testing the proposed methodology. It belongs to the basin of Overhead Tysa. The territory of selected area is the zone of prevailing development of "warm" water and mud-stone mudflows (Krasnook 2016). Data of cadastre-catalogue of mudflows of SE "Zahidukrgeologiya" (in a number of 252 units, over a period of 1998 - 2008) was used for realization of analysis.

The full-featured geographic information system MapInfo was selected as the basic GIS for the development of prognostic mudflow hazard system. A cartographic database was constructed and contained a cartographic layers of mudflows sites and factors which affects the regional development of mudflows within the area, such as geological (belonging to the lithological facies and tectonic zones, existence of landslides and tectonic faults), geomorphological (an angle of slope, altitude of mudflow sites and watersheds, distances to the watershed, base of erosion), technogenic (distances to the road and settlement), climatic (middle annual temperature of the air), and landscape (distance to the forest). 


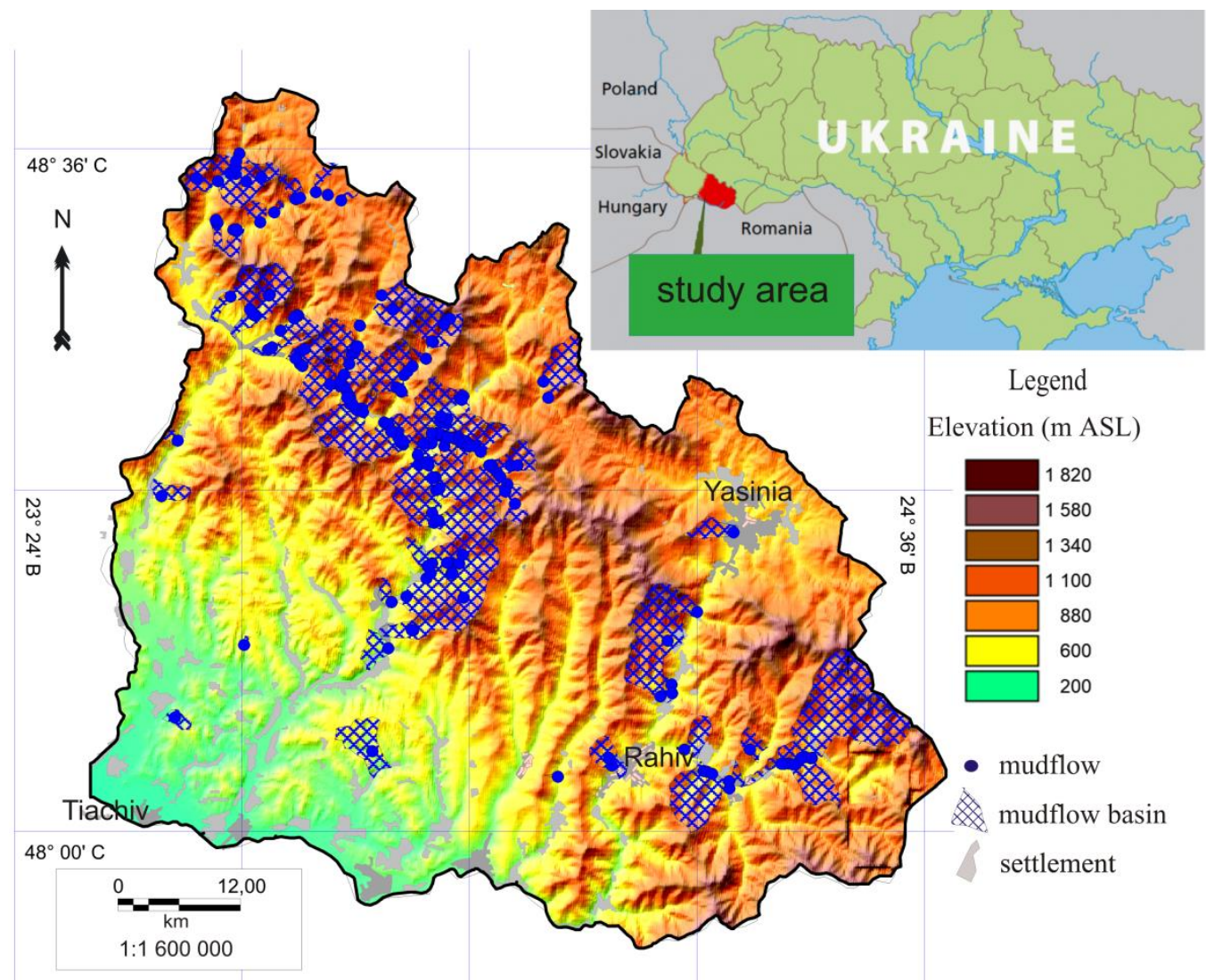

Fig.1. Location of the mudflow basins within the research area

A spatial analysis was conducted with application of metrical overlay operations with the purpose to verify the existence of patterns between mudflow sites distribution and factors, which in cartographic relation were mappingpoints, linear and planar objects. As a result, values of the following factor characteristics are calculated: altitude, angle of slope of surface, altitude of watershed, average annual amount of precipitation, distance to the road, to the base of erosion, to the limit of the forest and settlement, to the nearest landslide, to the tectonic fault, and to the watershed.

Searching of appropriate connection between the spatial distribution of mudflow sites and each of factors was executed by the verification of accordance of distribution of factor characteristics values by the theoretical distributions using of Kolmogorov-Smirnov criterion. Widen descriptive analysis have been presented in article (Chepurna, 2011). The final result of analysis, weighting coefficients are shown in table 1 .

SCSI was calculated by formula 3 . The histogram of distribution of SCSI is in Fig. 2. This distribution was taken to the consideration as a standard.

In a part of temporal analysis, time series of the following factor characteristics were selected: total annual amount of precipitation, average annual temperature of air, average annual ground water level, total annual energy of earthquakes, and Wolf numbers. The source of all data was cadastre-catalogue of $\mathrm{SE}$ "Zahidukrgeologiya", besides the Wolf numbers which were compiled by the US National Oceanic and Atmospheric Administration (the monthly averages of the daily sunspot number as posted at the WDCSILSO, Royal Observatory of Belgium, Brussels). Figure 3 shows input time series over observed periods. Such procedures were executed: normalization of values of 
characteristics and long-term mudflow activity with the aim of transformation into the dimensionless indexes of contrast; creation of auto - correlograms of the time series of factor characteristics and activity of mudflows. The analysis of autocorrelation functions and periodograms allowed defining basic rhythmic constituents in time series, given in the table.2.

Tab.1 Weighting coefficients of spatial factor characteristic

\begin{tabular}{|c|c|}
\hline $\begin{array}{l}\text { Spatial factor } \\
\text { characteristic }\end{array}$ & Weighting coefficients (\%) \\
\hline $\begin{array}{c}\text { Altitude of } \\
\text { mudflow site }\end{array}$ & 12.07 \\
\hline $\begin{array}{c}\text { Angle of slope of } \\
\text { surface of mudflow } \\
\text { site }\end{array}$ & 6.44 \\
\hline $\begin{array}{l}\text { Distance to the } \\
\text { road }\end{array}$ & 8.87 \\
\hline $\begin{array}{l}\text { Distance to the } \\
\text { base of erosion }\end{array}$ & 6.25 \\
\hline $\begin{array}{l}\text { Distance to the } \\
\text { limit of the forest }\end{array}$ & 7.68 \\
\hline $\begin{array}{l}\text { Distance to the } \\
\text { nearest landslide }\end{array}$ & 4.34 \\
\hline $\begin{array}{l}\text { Distance to } \\
\text { tectonic fault }\end{array}$ & 7.34 \\
\hline $\begin{array}{l}\text { Distance to the } \\
\text { watershed }\end{array}$ & 6.31 \\
\hline $\begin{array}{l}\text { Altitude of } \\
\text { watershed }\end{array}$ & 11.44 \\
\hline $\begin{array}{l}\text { Average annual } \\
\text { amount of } \\
\text { precipitation } \\
\text { (zone) }\end{array}$ & 8.56 \\
\hline $\begin{array}{l}\text { Infestation of lito- } \\
\text { facial zone }\end{array}$ & 9.79 \\
\hline $\begin{array}{l}\text { Infestation of } \\
\text { tectonic zone }\end{array}$ & 10.90 \\
\hline
\end{tabular}

Cross-correlation identified an appropriate displacement between time series of mudflow activity and Wolf numbers, and average annual temperature of air, and total annual temperature of air (1 year back for each of three); and average annual level of ground water (2 year forward). After the process of displacement correlation between series was observed on higher level (Fig.4). Weighting coefficients are approximately identical in numeral value, which means the absence of the dominant factor.

CIMA was expected by two methods without and with taking into account the series of mudflows activity. Time series of the calculated CIMA had periodicity of 10 . The indicated periodicity was equal to periodicity of the long-term mudflow activity within the investigated area.

\section{Results}

PGMMD was created following next steps.

The investigated territory was divided into squares $100 \times 100 \mathrm{~m}$. A new cartographic layer, that contains 104,437 points, was created from the grid. Values of factor characteristics in every point of grid were distinguished with application of overlay analysis.

Prognosis was executed for 2020 year, which was established as a year of the next pick of mudflow activity. Calculation of mudflow hazard was executed by the formula (9).

Prognosis maps of mudflow hazard were built as an interpolation maps and cartograms for basins of 3rd and 4th orders on the basis of created PGMMD. Thematic variable was chosen a mean value of mudflow hazard in a basin. Resulted cartogram is given in Figure 5.

Retroprognosis was carried out for verification of the offered methodology of spatio-temporal prognostication of mudflow hazard. The cartogram was built for basins of 3rd and 4th orders to 2008, and a comparison of the estimated mudflow hazard with registered mudflow ascents was made. From 20 registered mudflows 14 were observed within basins with very high mudflow hazard $(0,8-1) ; 4$ - within basins with high mudflow hazard $(0,6-0,8)$, just 2 mudflows were within basins with low mudflow hazard. In the basins with zero mudflow hazard no one fixed 
mudflow have not been gotten into. Thus, proposed prognostic model was relevant. As for the error of spatial prediction in any part of the territory, it was determined by the scale of maps and spatial accuracy. For the scale of the regional maps the error was estimated at $\pm 0,7$ $\mathrm{mm}$. So, for our studies that matched the scale 1:50 000, spatial prediction error was $\pm 35 \mathrm{~m}$.

Estimations of adjusted mudflow risks were calculated on the basis of PGMMD by formula 11. Detailed description of methodology of risk calculation given in next works (Chepurna, Kasiyanchuk, Kuzmenko, Eds. 2016, Kasiyanchuk 2016). Taking into account absence of protective complexes, the coefficient of $\mathrm{Z}$ was equated with one. Cartogram of mudflow risk assessment within the limits of administrative-territorial units (settlement and municipal advices) is given on Figure 6. Next village councils have got into the interval of maximal mudflow risks (0.0052-0.0115 people per year of maximum mudflow activity): Roztoky (Rakhiv district), Dubivetz (Tiachiv district), Negrovetz (Mizhgirya district).

\section{Scientific novelty and practical relevance}

The article presents the actual scientific solution of the problem - regional spatiotemporal prognosis of mudflow processes. The algorithm of spatio-temporal prognosis of mudflow hazard was offered, which contains the combined analysis of spatial and temporal factors of mudflow process development with application of modern geoinformational technologies and creation of prognostic geoinformational model of mudflow hazard.

Patterns of the distribution of mudflow sites were established in the territory of the eastern part of the Transcarpathia, which is reflected in SCSI. Periodicity of long-term mudflow activity was educed to the territory of the eastern part of the Transcarpathia, which was represented in CIMA. Prognosis was created by using all spatial and temporal factors, patterns and influence of which were established during this research.

The information concentrated in the article can be used by both research and project organizations, by scientific monitoring organization and future researches of mudflow processes. The educed patterns of mudflow processes development and factors of influence can be used in the construction of geoinformation models of mudflow hazard for geologically and geomorphological related territories; and taking into account of change of temporal factors accordions trend, it will be possible to construct such models for the next periods of time. A temporal model of longterm mudflows activity allows estimating the changes of long-term mudflow activity through the influence of factors, which presents practical interest for the aims of the corporate strategic planning of the development of regions, and can also be taken into account for the protective civil engineering.

Tab.2 Basic oscillation period of values of time series of factors and mudflow activity

\begin{tabular}{|c|c|}
\hline Temporal factors & The oscillation period of time series, years \\
\hline Total annual activity of mudflows & $5,10,21$ \\
\hline Wolf numbers & $10-11,21-22$ \\
\hline Total annual amount of precipitation & $3,6,21$ \\
\hline Average annual temperature of air & 10 \\
\hline Average annual groundwater level & $21-24$ \\
\hline Total annual energy of earthquakes & $8,11-13,21-22$ \\
\hline
\end{tabular}




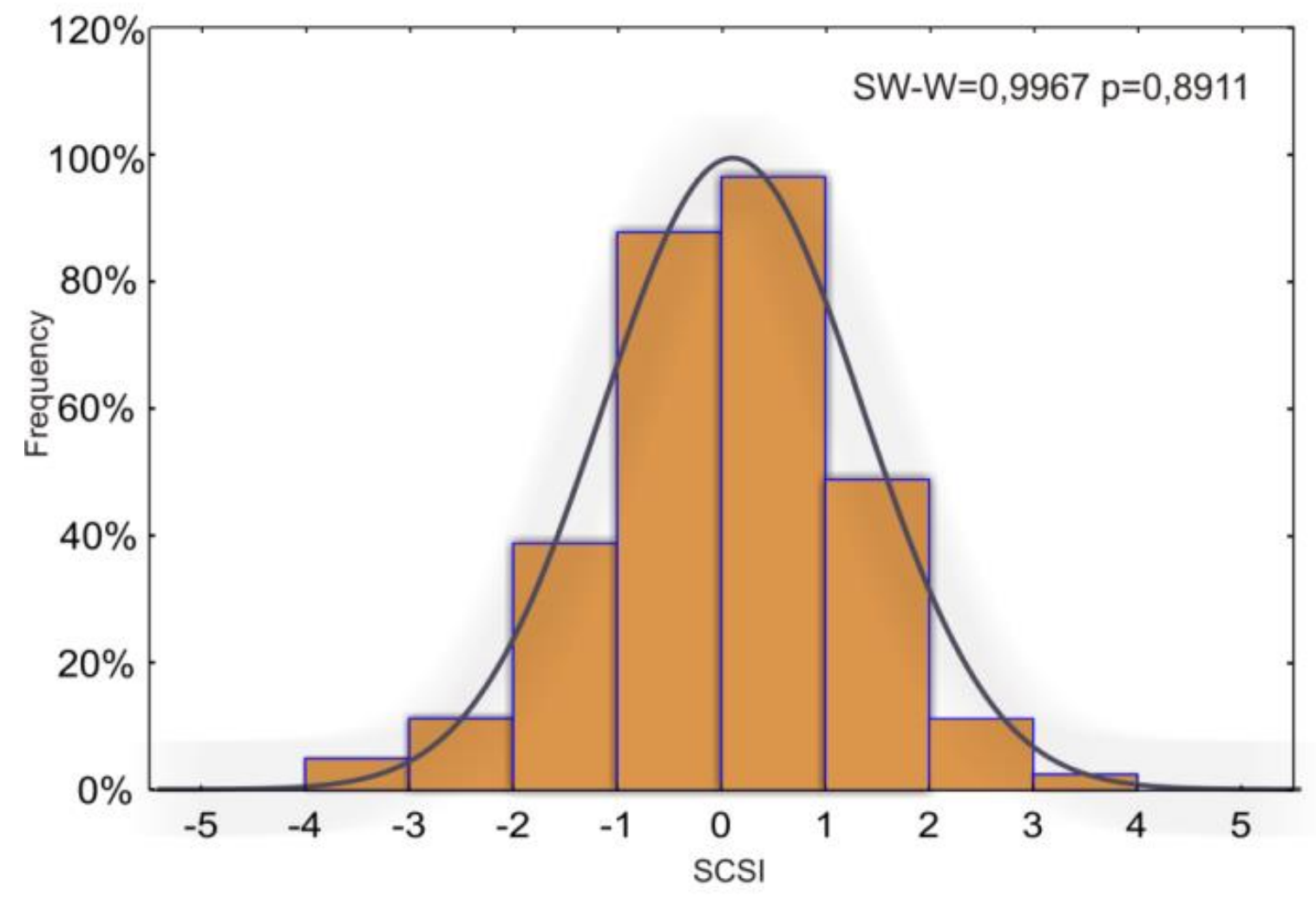

Fig.2. Histogram of distribution of SCSI

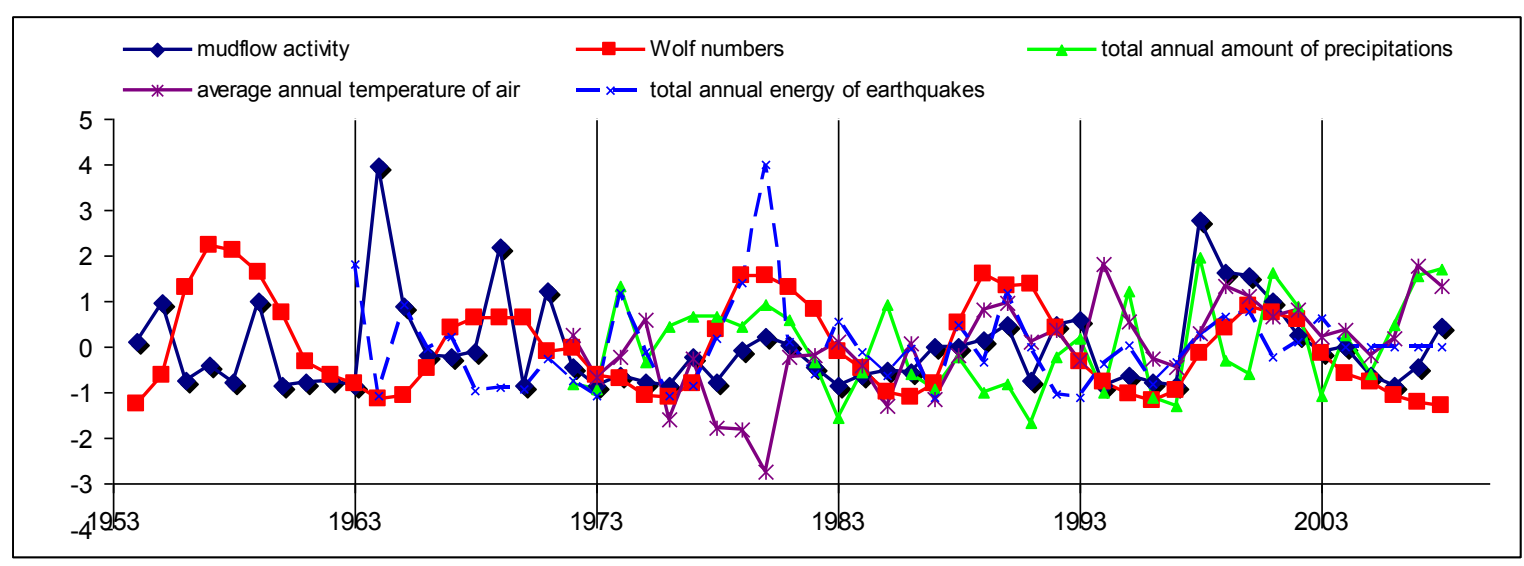

Fig.3. Graph of time series of mudflow activity and temporal factors over a period 


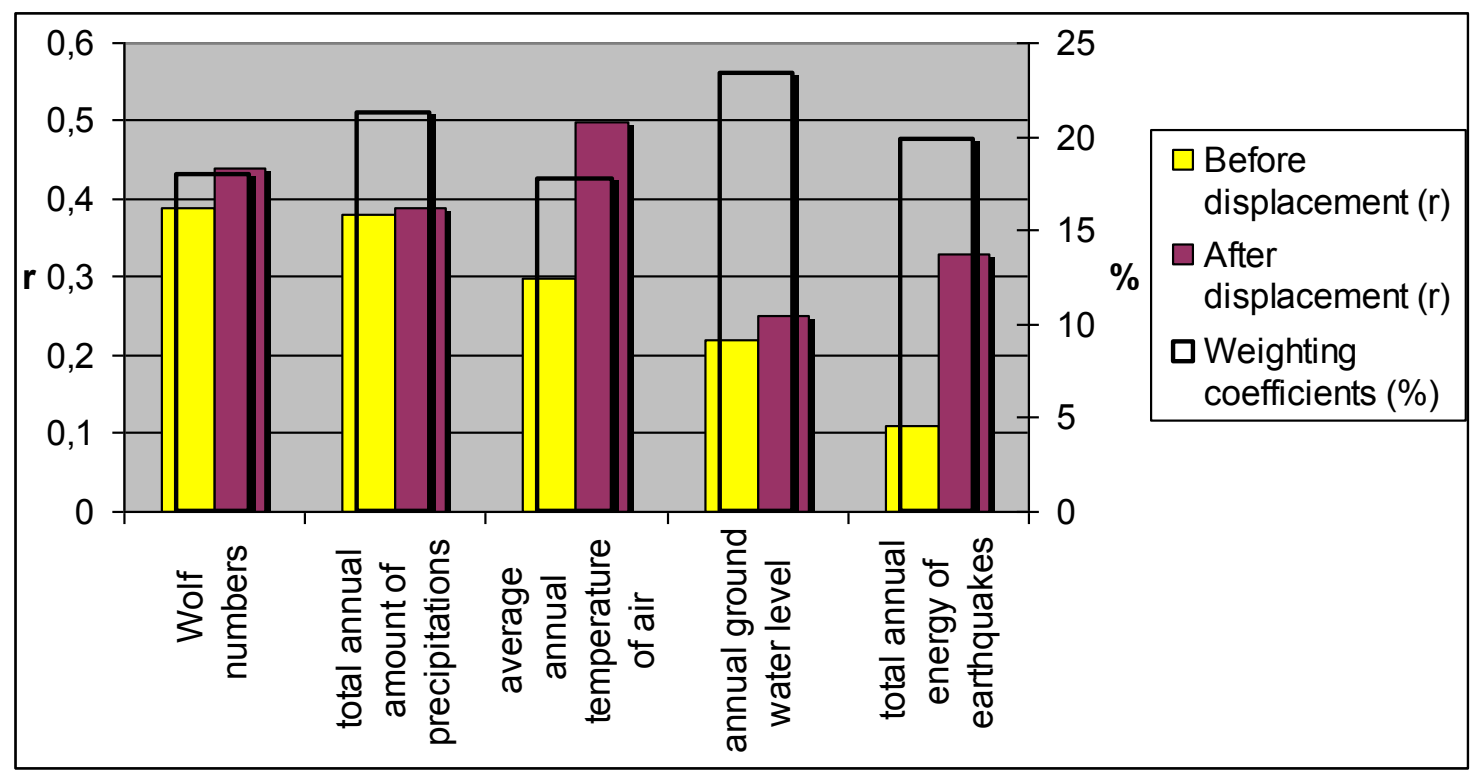

Fig.4. Graph of coefficients correlation between time series of mudflow activity and temporal factors, weighting coefficients of temporal factors

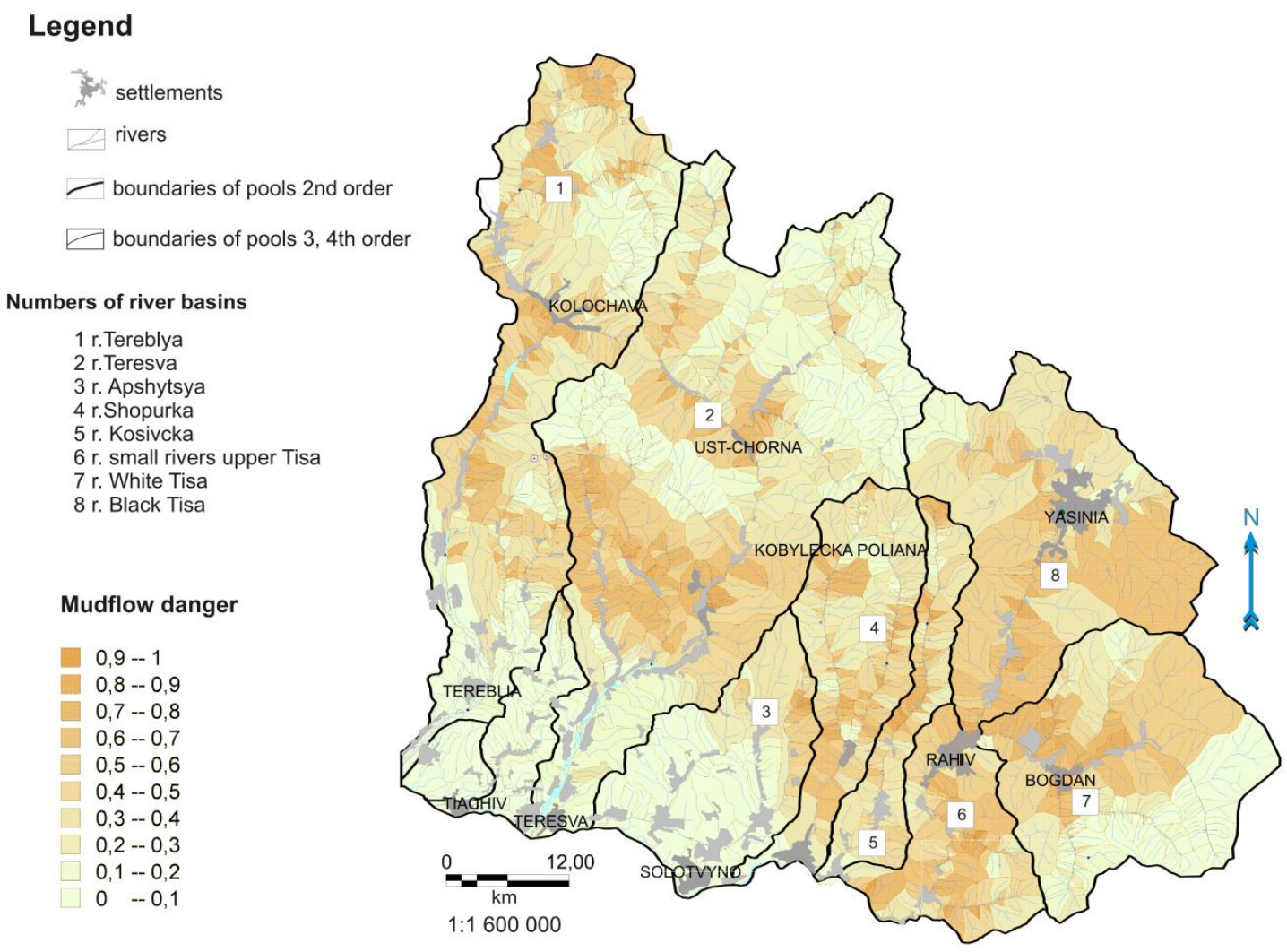

Fig.5. Cartogram of mudflow hazards in 2020 (eastern part of the Transcarpathian region) 


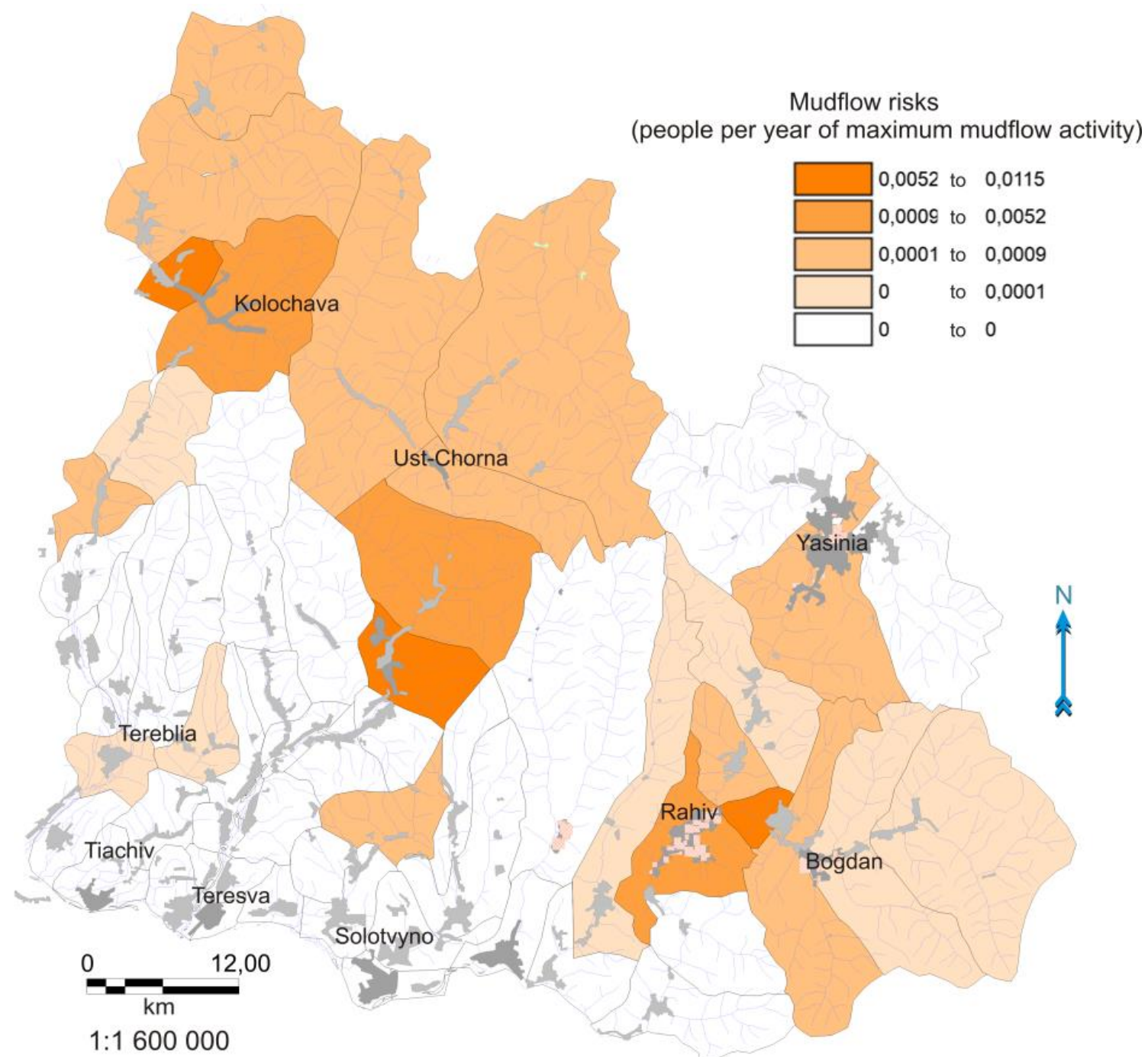

Fig.6. Cartogram of mudflow risk assessment within the limits of administrative-territorial units (settlement and municipal advices).

The prognostic cartographic model of mudflow hazard probability provides information about the possible emergency situations in areas with a high probability of mudflow hazard, and also allows forecasting of the mudflow processes development in those areas, where the field studies are not conducted.

\section{Conclusions}

The authors have developed a methodology of regional space-time prognosis of exogenous processes for purposes of forecasting of the mudflow hazard. Proposed methodology was based on the calculation of spatial and temporal indexes. The following sequence of research was proposed: the formation of cartographic database of possible factors, which could have influence on the development of mudflows; justification and selection of the relevant factors using statistical and spatial analysis, calculation of standard spatial complex indexes, building the longterm temporal model of mudflow activity; creating geoinformation cartographic predictive models of mudflow hazard.

In the quality of spatial, groups of factors and factor characteristics are introduced: as geological (belonging to the lithological facies 
and tectonic zones, existence of landslides and tectonic faults), geomorphological (an angle of slope, altitude of mudflow sites and watersheds, distances to the watershed, base of erosion), technogenic (distances to the road and settlement), climatic (middle annual temperature of the air in zone), and landscape (distance to the forest).

In the quality of temporal factors parameters such as heliophysics (Wolf numbers), seismic (energy of earthquakes), meteorological (amount of precipitation and temperature of air), hydrogeology (groundwater level), were selected.

The spatial prognosis of mudflow hazard was based on the detection of the regular connection between the spatial distribution of mudflow sites and the action of spatial factors. The temporal long-term prognosis of mudflow activity was based on a hypothesis about appropriate repetition of natural processes. Temporal model of CIMA was built on a basis of observed patterns and represented the educed 10-year regional periodicity of mudflow activity.

PGMMD was based on the complex spatial and temporal indexes. Forecast of mudflow hazard, was made on a basis by regarding model, for the territory of eastern part of the Transcarpathia for 2020, that was set as a year of next peak of mudflow activity.

This methodology was used for the estimation of mudflow risks for the territory of eastern part of Overhead Tysa basin. As a result, a cartogram of adjusted mudflow risks for administrative-territorial units (settlement and municipal advices) was created. Mudflow risks were counted for the year of maximum mudflow activity - 2020.

The presented models of mudflow hazard and risks for the part of the Carpathians presents a practical interest for regional government and emergency services. The educed dependence of mudflow processes development and factors of influence can be used for construction of mudflow hazard geoinformation models for geologically and geomorphological related territories.

\section{References}

Chepurna T.B. (2011) Regional spatialtemporal prediction of mudflow hazard using GIS technology. Dissertation, Taras Shevchenko National University of Kyiv.

Chepurna T.B., Kasiyanchuk D.V., Kuzmenko E.D., Eds. (2016) Methodology of quantitative forecasting of risk of development of exogenous geological processes: mudflow risks. Geoinformatika 2, 79-85.

Iverson R.M., Reid M. E., La Husen (1997) Debris-flow mobilization from landslides. Annual Review of Earth and Planetary Sciences 25 (1), 85-138.

Jakob M., Hungr O., Eds.(2005) Debris-Flow Hazards and Related Phenomena. PraxisSpringer, Berlin

Kasiyanchuk D. (2016) Calculation of ecological and geological risk of landslide hazard. International Journal of Applied Earth Observation and Geoinformation $1,18-25$

Krasnook L. (2016) Informational yearbook about hazardous of exogenous geological processes intensification according to their monitoring. - Kyiv; 2016. -89 p.

Kuzmenko E. (2011) Forecasting of exogenous processes. Part 1. Theoretical background of forecasting of exogenous geological processes. Patterns of activation of landslides. Geoinformatics 3, 61-74

Kuzmenko E.D., Chepurna T.B. (2014) Prognostication of mudflows in Ukrainian Carpathians. Geodynamika 1, 129-143

$\mathrm{Xu}$ J. (2008) A study on the integrated regional meteorological prognosis and warning model for geological hazards. Debris Flows: Disasters, Risk, Forecast, Protection:. Intern. conf, Pyatigorsk, -. Pyatigorsk, ?nstitut "Sevkavgiprovodkhoz" 178-181. 
Zhukov M. (2008) Mathematical statistics and processing of geological data. Kyyivkyy universtytet. - $487 \mathrm{p}$.

Zic E., Arbanas Z., Bicani N. Eds. (2015) A model of mudflow propagation downstream from the Grohovo landslide near the city of Rijeka (Croatia). Natural Hazards and Earth System Sciences 15, 293-31. 